\title{
DETECTION OF MAGNETIC INCLINATION ANGLE BY SEA TURTLES: A POSSIBLE MECHANISM FOR DETERMINING LATITUDE
}

\author{
KENNETH J. LOHMANN AND CATHERINE M. F. LOHMANN \\ Department of Biology, Coker Hall CB-3280, University of North Carolina, Chapel Hill, \\ NC 27599-3280, USA
}

Accepted 3 May 1994

\begin{abstract}
Summary
For animals that migrate long distances, the magnetic field of the earth provides not only a possible cue for compass orientation, but a potential source of world-wide positional information. At each location on the globe, the geomagnetic field lines intersect the earth's surface at a specific angle of inclination. Because inclination angles vary with latitude, an animal able to distinguish between different field inclinations might, in principle, determine its approximate latitude. Such an ability, however, has never been demonstrated in any animal.

We studied the magnetic orientation behavior of hatchling loggerhead sea turtles (Caretta caretta L.) exposed to earth-strength magnetic fields of different inclinations. Hatchlings exposed to the natural field of their natal beach swam eastward, as they normally do during their offshore migration. In contrast, those subjected to an inclination angle found on the northern boundary of the North Atlantic gyre (their presumed migratory path) swam south-southwest. Hatchlings exposed to an inclination angle found near the southern boundary of the gyre swam in a northeasterly direction, and those exposed to inclination angles they do not normally encounter, or to a field inclination found well within the northern and southern extremes of the gyre, were not significantly oriented.

These results demonstrate that sea turtles can distinguish between different magnetic inclination angles and perhaps derive from them an approximation of latitude. Most sea turtles nest on coastlines that are aligned approximately north-south, so that each region of nesting beach has a unique inclination angle associated with it. We therefore hypothesize that the ability to recognize specific inclination angles may largely explain how adult sea turtles can identify their natal beaches after years at sea.
\end{abstract}

\section{Introduction}

Loggerhead sea turtle hatchlings (Caretta caretta L.) embark on a long-distance migration immediately after emerging from their nests. Hatchlings from the east coast of Florida, USA, migrate eastward into the Gulf Stream current and the North Atlantic gyre (Carr, 1987). As the turtles grow, they apparently remain in the gyre for several years before eventually returning to the southeastern United States coast (Carr, 1986).

Key words: magnetic, orientation, magnetoreception, inclination, latitude, sea turtle, Caretta caretta. 
For hatchling Florida loggerheads, straying beyond the latitudinal extremes of the gyre can be fatal. As the northern edge of the gyre approaches Portugal, the east-flowing current abruptly divides. The northern branch continues past Great Britain and the water temperature decreases rapidly. Loggerheads swept north in this current soon die from the cold (Carr, 1986, 1987). Similarly, hatchlings that venture south of the gyre risk being swept into the south Atlantic current system and carried far from their normal range.

Loggerhead hatchlings possess a magnetic compass sense that may function in guiding their migration from the coast of Florida to the Gulf Stream current (Lohmann, 1991; Lohmann and Lohmann, 1994). The ability to detect the earth's magnetic field might also assist hatchlings in remaining within the North Atlantic gyre, if turtles can detect parameters of the earth's magnetic field that vary latitudinally.

Several magnetic parameters vary predictably over the surface of the earth. Among these, field line inclination is the most reliably correlated with latitude (Skiles, 1985). At each position on the globe, magnetic field lines intersect the earth's surface at a specific angle ranging from $0^{\circ}$ (parallel to the earth) at the geomagnetic equator to $90^{\circ}$ at the magnetic poles. Thus, an animal capable of distinguishing between different inclination angles might determine its approximate latitude.

To determine whether migrating hatchlings can derive positional information from the inclination of magnetic field lines, we studied the orientation behavior of turtles exposed to earth-strength magnetic fields of different inclinations. We report that different inclination angles elicited different directional responses from hatchlings and that such responses may normally function to keep turtles within the boundaries of the North Atlantic gyre. Thus, sea turtles can distinguish between different magnetic inclination angles and possess a functional means of approximating latitude.

\section{Materials and methods}

\section{Animals}

Hatchling loggerhead turtles were obtained from nests deposited on beaches in Boca Raton, Florida, USA. Nests were checked daily in the late afternoon. When a depression formed in the sand above the eggs (indicating that emergence was imminent), we gently dug into the nest and removed 10-18 hatchlings. The turtles were immediately placed into a light-proof Styrofoam cooler and transported to a laboratory approximately $5 \mathrm{~km}$ away. Hatchlings were maintained in complete darkness until testing. Each turtle was tested only once during its first night of captivity, then released.

\section{Orientation arena and data acquisition}

Hatchlings were tested in a circular, fiberglass tank $1.22 \mathrm{~m}$ in diameter. The tank was filled with sea water to a depth of about $15 \mathrm{~cm}$. In each trial, a hatchling was placed into a nylon-Lycra harness that encircled its carapace without impeding swimming. The harness was connected by a monofilament line to a Plexiglas lever-arm. The lever-arm rested on a digital encoder inside a plastic post mounted in the center of the arena (Fig. 1). The lever-arm was free to rotate in any direction and tracked the orientation of the turtle 
as it swam. The digital encoder in the central post was wired to a computer in an adjacent room. The computer recorded the position of the turtle (to the nearest $1.4^{\circ}$ ) every $10 \mathrm{~s}$.

\section{Control of the ambient magnetic field}

A computer-driven magnetic coil system produced earth-strength magnetic fields with different inclinations. The coil system consisted of two independent four-coil systems (Merritt et al. 1983) arranged orthogonally (Fig. 1). The first coil was aligned with the north-south magnetic axis and could be used to control the magnitude of the horizontal field component. The second coil controlled the vertical field component. Current to each coil was provided by a computer-controlled power supply. Software developed for the system enabled us to specify the intensity and inclination of the field. Thus, fields of equal intensity but different inclination could be generated by entering the desired parameters into the computer.

To confirm field parameters, we measured the horizontal and vertical field components inside the orientation arena with a Schonstedt single-axis fluxgate digital magnetometer (model DM $2220 \mathrm{R}$ ). The inclination angle and total field intensity were calculated from these values. Inclination angles measured in the zone where hatchlings swam were found to be within $\pm 0.5^{\circ}$ of the values specified by computer. The measured total field intensity for each condition was $0.044-0.045 \mathrm{mT}$.

The two computers (one for data acquisition, one for the coil) and all power supplies were located in an adjacent room away from the coil. All computers and power supplies remained on in all trials, so that sounds or vibrations (e.g. from cooling fans) were the same regardless of the inclination angle.

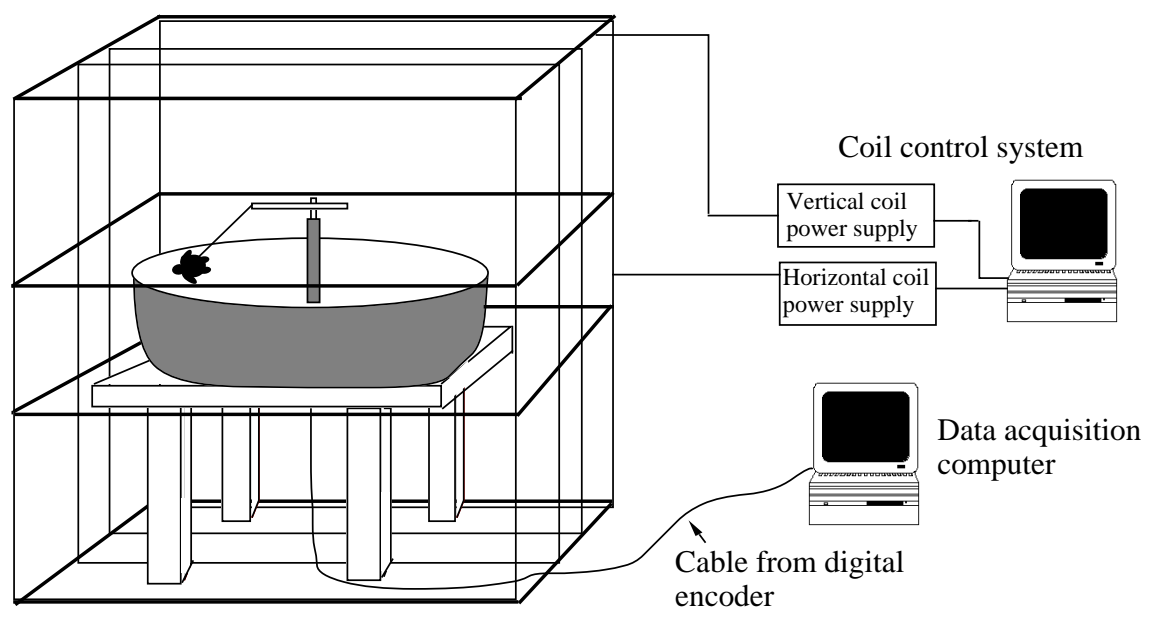

Fig. 1. The orientation arena, coil system for generating earth-strength magnetic fields of different inclinations, data acquisition system and coil control system. Each hatchling was tethered to a rotatable lever-arm mounted on a digital encoder (which was inside the central post of the orientation arena). The lever-arm thus tracked the direction towards which the turtle swam in darkness. Signals from the digital encoder were relayed to the data acquisition computer which recorded the orientation of the turtle every $10 \mathrm{~s}$. Details of the magnetic coil system are given in the text. 


\section{Testing procedure}

All experiments were conducted in July and August, 1993. Trials were carried out at night between 20:00 $\mathrm{h}$ and 03:00 h, the time when most loggerhead hatchlings emerge from their nests and enter the sea (Witherington et al. 1990).

Prior to each trial, all lights in the room were turned off except for a dimly illuminated light bulb (Lohmann, 1991) suspended $2-3 \mathrm{~cm}$ above the water in the east. Each hatchling was harnessed and released in the orientation arena in the local magnetic field. As in previous experiments (Salmon and Wyneken, 1987; Lohmann, 1991; Light et al. 1993), most hatchlings (approximately $85 \%$ ) quickly established a course towards the light $\left( \pm 45^{\circ}\right)$.

The light was presented because hatchlings that enter the ocean on dark, natural beaches encounter a dim glow of reflected skylight along the seaward horizon, and such light cues may play a role in establishing the magnetic directional preference of hatchlings leaving their natal beaches (Lohmann, 1991; Lohmann and Lohmann, 1994). In addition, the response of each hatchling to the light source served to verify that the turtle was healthy and capable of maintaining an oriented course. Those few turtles that failed to establish a course towards the light within about $3 \mathrm{~min}$ were replaced with other hatchlings.

After a turtle had swum towards the light for $10 \mathrm{~min}$, the light was turned off, and the hatchling swam in darkness during the ensuing test period. Four previous experiments have demonstrated that hatchlings swimming in darkness under these conditions orient using the earth's magnetic field (Lohmann, 1991; Light et al. 1993; Lohmann and Lohmann, 1993, 1994).

In all trials except for controls, the inclination angle of the field was changed 1-2 s after the light had been turned off. Each field change was accomplished in a single step, so that the total field intensity remained constant. In control trials, the ambient field was not altered when the light was turned off. Turtles were given $3 \mathrm{~min}$ to adjust to the new conditions. Data acquisition then began, and the position of the turtle was recorded each $10 \mathrm{~s}$ for the next $5 \mathrm{~min}$.

Two series of experiments were conducted. The first series consisted of three inclination angles: $57^{\circ}$ (the local inclination), $15^{\circ}$ and $75^{\circ}$. The second series consisted of another three inclination angles: $60^{\circ}, 45^{\circ}$ and $30^{\circ}$. In each series of experiments, we alternated between the three treatments (i.e. in the first series the first turtle was tested at $57^{\circ}$, the second at $15^{\circ}$, the third at $75^{\circ}$, the fourth at $57^{\circ}$, and so on). Each hatchling was tested only once (i.e. under just one of the six inclination angles).

\section{Statistics}

At the conclusion of each trial, the computer calculated a mean angle for each hatchling (Batschelet, 1981) using all of the $10 \mathrm{~s}$ measurements obtained during the $5 \mathrm{~min}$ test period in darkness. The mean angles for each group of hatchlings were then analyzed with a Rayleigh test (Batschelet, 1981) to determine whether turtles tested under each inclination angle were significantly oriented. Because we predicted that hatchlings tested in the local earth's field would orient eastward (on the basis of previous results, Light 
et al. 1993; Lohmann and Lohmann, 1994), the results obtained in the local field were also analyzed with a $V$-test (Batschelet, 1981) in which the predicted direction was $90^{\circ}$.

A Mardia-Watson-Wheeler test was used to determine whether the orientation of the hatchlings differed among groups tested under the six different inclination angles.

\section{Results}

Results are shown in Fig. 2. Hatchlings tested in the local geomagnetic field (inclination angle $57^{\circ}$ ) were significantly oriented eastward (Fig. 2, top left). In addition,

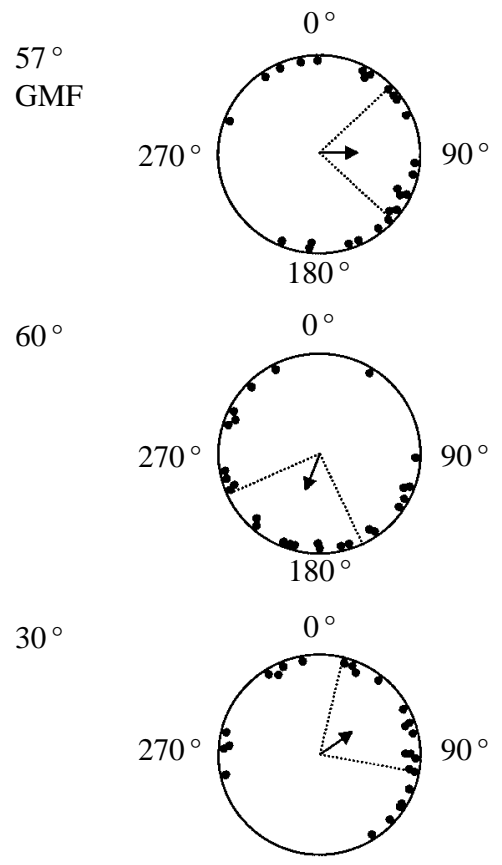

$180^{\circ}$
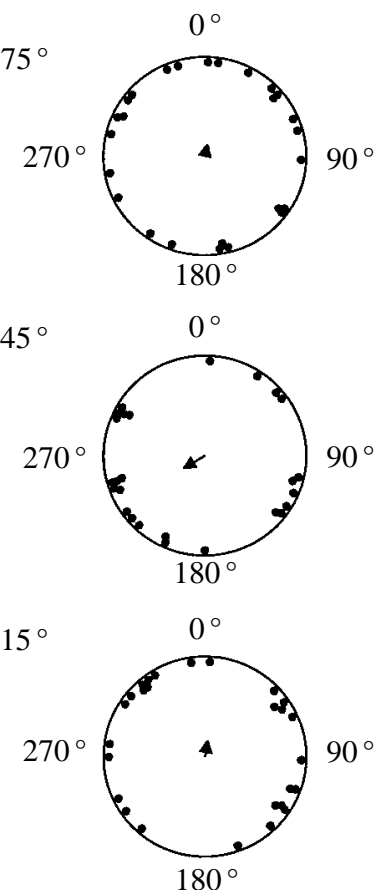

Fig. 2. Orientation of hatchling loggerheads swimming in magnetic fields of identical intensity but different inclinations. The position of each dot indicates the mean angle of a single hatchling. Arrows in the center of each circle indicate the mean angle of the group. The arrow length is proportional to the magnitude of the mean vector $\mathbf{r}$, with the radius of the circle corresponding to $\mathbf{r}=1$. Dashed lines indicate the $95 \%$ confidence interval for the mean angle in the three distributions that were significantly oriented (Batschelet, 1981). The inclination angle in which each group was tested is indicated to the left of each figure; GMF indicates the local geomagnetic field (inclination angle $57^{\circ}$ ). Hatchlings tested in the local geomagnetic field were significantly oriented eastwards (mean angle $=90^{\circ}, N=26, \mathbf{r}=0.40, P<0.017$, Rayleigh test; $U=2.88, P<0.005, V$-test with predicted direction of $\left.90^{\circ}\right)$. Turtles tested under an inclination angle of $60^{\circ}$ were significantly oriented south-southwest (mean angle $=200^{\circ}$, $N=26, \mathbf{r}=0.38, z=3.70, P<0.025$, Rayleigh test) and those tested under a $30^{\circ}$ inclination angle oriented significantly towards the northeast (mean angle $=57^{\circ}, N=26, z=4.15, P<0.017$, Rayleigh test). Hatchlings were not significantly oriented in fields with inclinations of $75^{\circ}$ $(N=26, \mathbf{r}=0.11, z=0.33), 45^{\circ}(N=26, \mathbf{r}=0.23, z=1.39)$ or $15^{\circ}(N=27, \mathbf{r}=0.17, z=0.74)$. See text for additional detail. 
hatchlings were significantly oriented under two of the five inclination angles not found on their natal beach. Turtles tested under an inclination angle of $60^{\circ}$ were significantly oriented south-southwest (Fig. 2, middle left). In contrast, those tested under a $30^{\circ}$ inclination angle oriented significantly towards the northeast (Fig. 2, bottom left).

Hatchlings were not significantly oriented (Rayleigh test) under three inclination angles not found on the natal beach $\left(75^{\circ}, 45^{\circ}\right.$ and $15^{\circ}$; Fig. 2, right).

A multi-sample comparison with a Mardia-Watson-Wheeler test indicated significant differences among the six distributions $(W=26.178, P<0.005)$. Thus, inclination angle influenced the orientation behavior of sea turtle hatchlings.

\section{Discussion}

Hatchlings exposed to the inclination angle of their natal beach $\left(57^{\circ}\right)$ were significantly oriented towards the east (Fig. 2), as has been observed in several previous studies using similar procedures (Lohmann and Lohmann, 1993, 1994; Light et al. 1993). This eastward orientation probably represents a magnetic directional preference acquired on the basis of the light cues provided at the start of each trial (Lohmann and Lohmann, 1994). Under natural conditions, when such cues are provided by the ocean horizon, this response may function in guiding hatchlings eastward from the coast of Florida to the Gulf Stream current.

Whereas hatchlings tested in the local geomagnetic field oriented eastward, those tested in an identical field with an inclination angle only $3^{\circ}$ greater $\left(60^{\circ}\right)$ were significantly oriented towards the south-southwest. In addition, hatchlings exposed to fields inclined at $75^{\circ}, 45^{\circ}$ and $15^{\circ}$ had orientation statistically indistinguishable from random, and turtles in a field with a $30^{\circ}$ inclination swam northeast (Fig. 2). Because the intensity of the field was the same in each case, these results demonstrate that sea turtles can distinguish between magnetic fields differing only in inclination. Thus, sea turtles appear to possess a functional means of determining latitude.

\section{Inclination angles at the latitudinal extremes of the North Atlantic gyre}

Hatchlings oriented significantly under two of the five inclination angles $\left(60^{\circ}\right.$ and $\left.30^{\circ}\right)$ not found on the natal beach. Why turtles oriented under these conditions, and not under $15^{\circ}, 45^{\circ}$ or $75^{\circ}$ field inclinations, is not known. We speculate, however, that the significant directional preferences hatchlings manifested under $60^{\circ}$ and $30^{\circ}$ field inclinations may reflect responses that function to keep hatchlings within the latitudinal extremes of the North Atlantic gyre.

After swimming into the Gulf Stream from the coast of Florida, hatchlings remain in the current as it veers eastward across the Atlantic (Carr, 1987). Near the coast of Portugal, the current divides, with the northern half continuing past Great Britain as the North Atlantic Drift (Fig. 3). The water temperature, once around $25^{\circ} \mathrm{C}$, decreases rapidly, and loggerheads caught in the northern current soon succumb to cold (Carr, 1986).

The split in the Gulf Stream occurs near the $60^{\circ}$ isoclinic (Fig. 3). In our experiments, hatchlings subjected to an inclination angle of $60^{\circ}$ swam south-southwest (Fig. 2). If 


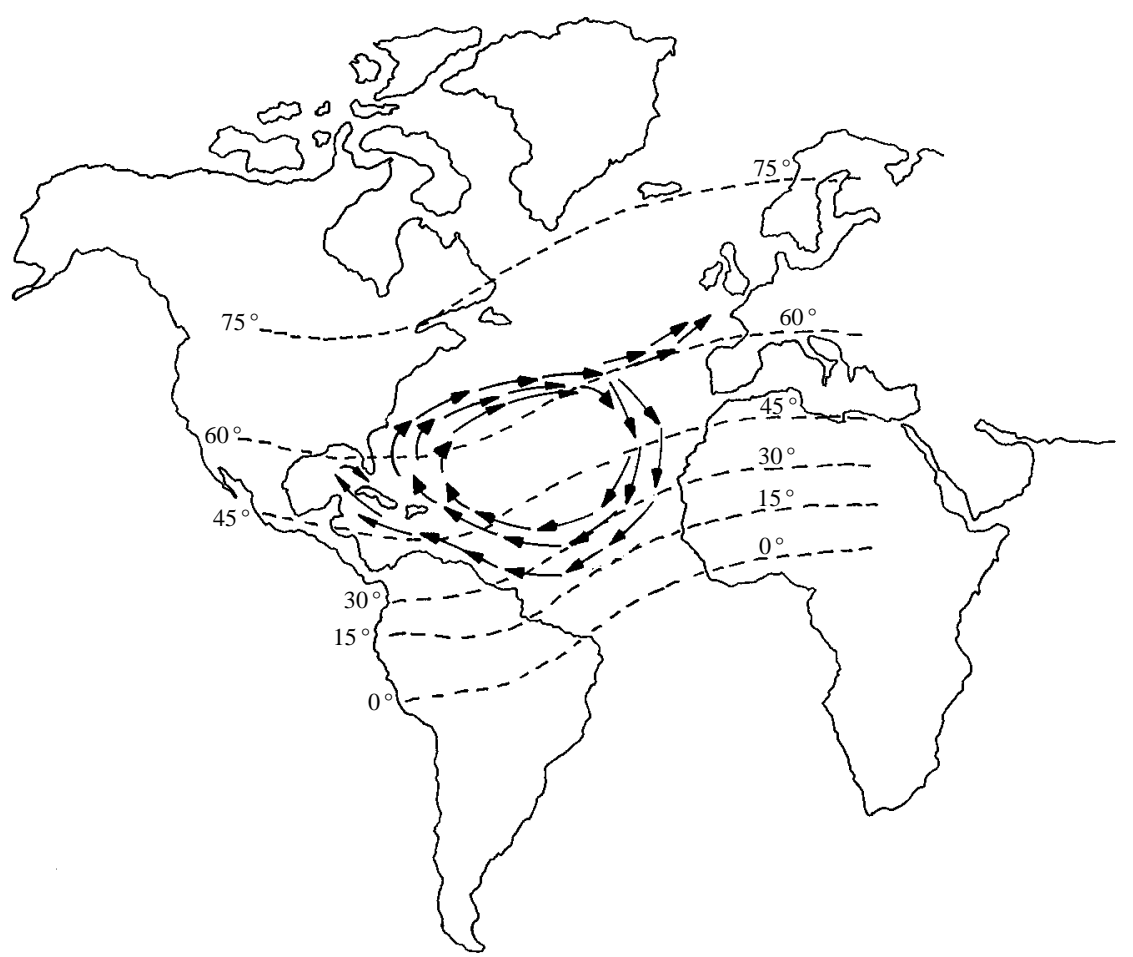

Fig. 3. Diagram of the North Atlantic gyre and inclination angles. Isoclinics (lines of equal inclination) are represented by dashed lines; numbers indicate inclination angles in degrees. Currents of the North Atlantic gyre are represented by arrows, with the North Atlantic Drift branching off from the northeastern corner of the gyre. Isoclinics are adapted from Skiles (1985). North Atlantic gyre is drawn after Gross (1977) and Carr (1986).

hatchlings in the gyre normally swim south when encountering inclination angles marking the northern boundary of the gyre (about $60-67^{\circ}$ ), they may reduce their chances of being swept north into fatally low temperatures when the Gulf Stream divides.

In contrast to the southerly orientation of hatchlings tested in a field inclined $60^{\circ}$, turtles tested in a field inclined $30^{\circ}$ were significantly oriented towards the northeast (Fig. 2). In the northern Atlantic, a $30^{\circ}$ inclination angle is found near the southern edge of the gyre system (Fig. 3). By swimming in a northeasterly direction in this region (or better still, towards the north), turtles might reduce their chances of straying out of the gyre into locations farther south.

\section{Absence of significant orientation in fields with $75^{\circ}, 45^{\circ}$ and $15^{\circ}$ inclinations}

Hatchlings exposed to inclination angles of $75^{\circ}, 45^{\circ}$ and $15^{\circ}$ were not significantly oriented as a group. Two of these inclination angles occur either north $\left(75^{\circ}\right)$ or south $\left(15^{\circ}\right)$ of the gyre's normal boundaries, at latitudes turtles probably never encounter as hatchlings. Thus, the failure to orient under these two conditions $\left(75^{\circ}\right.$ and $\left.15^{\circ}\right)$ may reflect a lack of motivation to swim towards a specific direction when confronted with such unnatural magnetic parameters. 
An alternative interpretation is that the magnetic compass was unable to function in fields with inclinations of $75^{\circ}$ or $15^{\circ}$. The turtle magnetic compass (Light et al. 1993), like that of birds (Wiltschko and Wiltschko, 1972, 1988), is an inclination compass that apparently fails to distinguish field polarity (i.e. north from south); instead it defines 'poleward' as the direction along the earth's surface in which the angle formed between the total field vector and the gravity vector is smallest. For this reason, an inclination compass cannot function if the inclination angle is $0^{\circ}$ (as is found at the magnetic equator) or $90^{\circ}$ (as occurs at the magnetic poles). The failure of turtles to orient under $75^{\circ}$ and $15^{\circ}$ inclinations might therefore result from an inability of the compass to function when the ambient field is nearly horizontal or vertical. At least one species of bird, the migratory wheatear Oenanthe oenanthe, however, is able to orient magnetically in fields with inclinations as steep as $81^{\circ}$ (Sandberg et al. 1991).

The absence of significant orientation under a $45^{\circ}$ inclination angle appears unlikely to result from an inability of the compass to function in this field, given that turtles can orient in fields inclined both more $\left(60^{\circ}, 57^{\circ}\right)$ or less $\left(30^{\circ}\right)$ steeply. Because a $45^{\circ}$ inclination angle corresponds to positions well within the gyre's latitudinal extremes, we speculate that drifting with prevailing currents poses no immediate threat to a turtle anywhere along the $45^{\circ}$ isoclinic. Thus, the absence of significant group orientation under this condition might reflect a lack of motivation by hatchlings to swim towards a single specific direction.

\section{Deriving world-wide positional information from magnetic parameters}

Evidence that magnetic parameters may assist migratory animals in global positionfinding has been previously reported in one bird, the pied flycatcher Ficedula hypoleuca (Beck, 1984; Beck and Wiltschko, 1986). Captive flycatchers exposed to a sequence of changes in both magnetic field intensity and inclination angle (such as that normally encountered along the migratory route) shifted orientation in the same direction and at the same time as conspecifics during the natural migration. Such shifts in orientation did not occur in birds maintained in the ambient field at the starting point of the migration, or in birds kept in a constant field found at the migration endpoint. These data suggest a complex interaction between an endogenous time program and magnetic parameters, in which the birds must apparently experience sequentially the magnetic parameters of specific locations at the appropriate times in order to orient appropriately at each point in the migration.

Whether sea turtles have similar endogenous time programs that influence migratory orientation is not known. In our experiments, hatchlings exposed to $60^{\circ}$ and $30^{\circ}$ inclination angles swam in nearly opposite directions (Fig. 2), even though hatchlings in the gyre probably encounter the first condition several months before the second (Carr, 1986). These results suggest that inclination angles alone are sufficient to elicit specific orientation responses in hatchlings. Nevertheless, the possibility remains that other factors normally alter or modulate responses to inclination angles under more natural conditions. Endogenous time programs, prior experience (such as sequentially encountering different magnetic conditions) or other, as yet unidentified, factors might all influence the directional tendencies of migrating turtles.

In addition, it is important to recognize that the magnetic parameters hatchlings 
encountered in the laboratory did not fully reproduce the magnetic conditions turtles actually encounter within the North Atlantic gyre. Like inclination angle, the total intensity of the earth's field varies with latitude (Skiles, 1985). Because we held field intensity constant in all of our experiments, only hatchlings tested in the local earth's field experienced inclination and intensity combinations that actually occur together in the North Atlantic. Whether matching each inclination angle with its 'correct' field intensity for the North Atlantic would alter the responses we observed (Fig. 2) remains to be determined.

\section{Inclination angle detection}

Our experiments demonstrate for the first time that an animal can distinguish between different magnetic inclination angles. Whether this discrimination is accomplished by detecting inclination angle per se, however, remains to be determined. Inclination angle varies in concert with the relative magnitudes of the horizontal and vertical field components; thus, the intensity of each vector component, like the inclination angle itself, varies with latitude (Skiles, 1985). If turtles can resolve the total geomagnetic field into its constituent components and monitor the intensity of one or both, then they might distinguish between fields of different inclinations without directly sensing the angle.

Whether any animal can monitor the intensity of a single vector component of the earth's field, however, is not known. Both turtles (Light et al. 1993) and birds (Wiltschko and Wiltschko, 1972) appear to detect the total field vector. For this reason, we presently favor the hypothesis that turtles detect the inclination angle itself, but definitive experiments remain to be carried out.

\section{Inclination angles and navigation of adult turtles}

Adult female sea turtles display remarkable nesting site fidelity, often returning to the same, specific stretch of beach to lay their eggs during successive nesting seasons (Limpus et al. 1992). Recent mitochondrial DNA analyses have provided evidence that the beaches to which turtles return are the same ones they hatched on years before (Bowen et al. 1993).

The ability to distinguish between inclination angles might largely explain how adult sea turtles can locate a specific region of coastline after years at sea. Most nesting beaches are aligned north-south (e.g. the east coast of North America) or are small islands (e.g. Ascension Island in the mid-Atlantic). Each nesting beach therefore has a different inclination angle associated with it.

If a hatchling imprints on or learns the inclination angle of its natal beach, finding the beach as an adult years later might be relatively simple. To locate a specific nesting beach on the east coast of Florida, for example, a turtle might merely swim along the North American coastline until it encounters the appropriate inclination angle, then go ashore. Indeed, a turtle swimming anywhere in the North Atlantic might reliably arrive at its natal beach simply by swimming north or south until it finds the proper inclination angle, then swimming west along the isoclinic until it reaches land.

Similar recognition of a specific inclination angle, perhaps combined with swimming along an isoclinic, might explain some of the most spectacular navigational feats of sea turtles, including the ability of green turtles to locate tiny Ascension Island in the mid- 
Atlantic (Carr, 1975) and the ability of Kemp's ridleys to return to a specific nesting beach at Rancho Nuevo, Mexico (Carr, 1963).

We thank Jay Callaway for developing the data acquisition system, Beth Manning and Holly Cate for technical assistance, and Mike Salmon and Jeanette Wyneken for providing summer laboratory facilities for us in Boca Raton. Research on a threatened species was authorized under Florida DNR special permit TP 065. The work was supported by NSF grant IBN-9120338.

\section{References}

Batschelet, E. (1981). Circular Statistics in Biology. London: Academic Press.

BECK, W. (1984). The influence of the earth magnetic field to the migratory behaviour of pied flycatchers (Ficedula hypoleuca Pallas). In Localization and Orientation in Biology and Engineering (ed. D. Varju and H.-U. Schnitzler), pp. 357-359. Berlin: Springer Verlag.

BECK, W. AND WILTSChKo, W. (1986). Magnetic factors control the migratory direction of pied flycatchers (Ficedula hypoleuca Pallas). In Acta XIX Congressus Internationalis Ornitholgici, vol. II (ed. H. Ouellet), pp. 1955-1962. Ottawa: University of Ottawa Press.

Bowen, B., Avise, J. C., Richardson, J. I., Meylan, A. B., Margaritoulis, D. And Hopkins-Murphy, S. R. (1993). Population structure of loggerhead turtles (Caretta caretta) in the northwestern Atlantic Ocean and Mediterranean Sea. Cons. Biol. 7, 834-844.

CARr, A. (1963). Panspecific reproductive convergence in Lepidochelys kempi. Ergeb. Biol. 26, 298-303.

CARR, A. (1975). The Ascension Island green turtle colony. Copeia 3, 547-555.

CARR, A. (1986). Rips, FADS and little loggerheads. Bioscience 36, 92-100.

CARr, A. (1987). New perspectives on the pelagic stage of sea turtle development. Cons. Biol. 1, 103-121.

Gross, M. G. (1977). Oceanography. Englewood Cliffs, New Jersey: Prentice-Hall, Inc.

Light, P., SALMON, M. AND LohmanN, K. J. (1993). Geomagnetic orientation of loggerhead sea turtles: evidence for an inclination compass. J. exp. Biol. 182, 1-10.

Limpus, C. J., Miller, J. D., Parmenter, C. J., Reimer, D., Mclachland, N. and WebB, R. (1992). Migration of green (Chelonia mydas) and loggerhead (Caretta caretta) turtles to and from eastern Australian rookeries. Wildlife Res. 19, 347-358.

Lohmann, K. J. (1991). Magnetic orientation by hatchling loggerhead sea turtles (Caretta caretta). J. exp. Biol. 155, 37-49.

Lohmann, K. J. And Lohmann, C. M. F. (1993). A light-independent magnetic compass in the leatherback sea turtle. Biol. Bull. mar. biol. Lab., Woods Hole 185, 149-151.

Lohmann, K. J. And Lohmann, C. M. F. (1994). Acquisition of magnetic directional preference in hatchling loggerhead sea turtles. J. exp. Biol. 190, 1-8.

Merritt, R., PurCell, C. AND Stroink, G. (1983). Uniform magnetic field produced by three, four and five square coils. Rev. sci. Instrum. 54, 879-882.

SALMON, M. AND WynEKEN, J. (1987). Orientation and swimming behavior of hatchling loggerhead turtles (Caretta caretta L.) during their offshore migration. J. exp. mar. Biol. Ecol. 109, 137-153.

SAndBerg, R., Ottosson, U. AND PetTersson, J. (1991). Magnetic orientation of migratory wheatears (Oenanthe oenanthe) in Sweden and Greenland. J. exp. Biol. 155, 51-64.

SKILES, D. D. (1985). The geomagnetic field: its nature, history and biological relevance. In Magnetite Biomineralization and Magnetoreception in Organisms (ed. J. L. Kirschvink, D. S. Jones and B. J. MacFadden), pp. 43-102. New York: Plenum Press.

WiltschKo, W. AND WiltschKo, R. (1972). Magnetic compass of European robins. Science 176, 62-64. WiltschKo, W. AND WiltschKo, R. (1988). Magnetic orientation in birds. In Current Ornithology, vol. 5 (ed. R. F. Johnston), pp. 67-121. New York: Plenum Press.

Witherington, B. E., Bjorndal, K. A. AND McCABE, C. M. (1990). Temporal pattern of nocturnal emergence of loggerhead turtle hatchlings from natural nests. Copeia 4, 1165-1168. 